\title{
In-situ comparison of thermal measurement technologies for interpretation of PV module temperature de-rating effects
}

\author{
Teri Elwood, Whit Bennett, Teh Lai, and Kelly Simmons-Potter \\ University of Arizona, Tucson, AZ 85721
}

\begin{abstract}
It is well known that the efficiency of a photovoltaic (PV) module is strongly impacted by its temperature such that higher temperatures lead to lower energy conversion efficiencies. An accurate measurement of the temperature de-rating effect, therefore, is vital to the correct interpretation of PV module performance under varied environmental conditions. The current work investigates and compares methods for performing measurements of module temperature both in the lab and in field-test environments. A comparison of several temperature measurement devices was made in order to establish the ideal sensor configuration for quantifying module operating temperature. Sensors were also placed in various locations along a string of up to eight photovoltaic modules to examine the variance in operating temperature with position in the string and within a larger array of strings.
\end{abstract}

Keywords: photovoltaic, temperature de-rating, operating temperature, temperature sensors, PV array temperature

\section{INTRODUCTION}

It has been clearly established that the efficiency of a PV module is impacted by its operating temperature ${ }^{[1-4]}$, which is a function of factors such as ambient air temperature, solar irradiance, and local weather conditions. Higher operating temperatures lead to lower PV energy conversion efficiencies; a phenomenon known as the temperature de-rating effect. Furthermore, it is known that the power-generating efficiency of PV modules diminishes over time due to prolonged exposure to environmental conditions which, in turn, has significant consequences for PV performance lifetimes ${ }^{[4-7]}$. Specifically, temperature extremes and elongated exposure to solar radiation are responsible for many modes of failure in PV modules ${ }^{[4,8-12]}$. Thus, proper interpretation of PV failure rates and lifetimes requires the accurate extraction of insitu temperature de-rating effects from overall module degradation effects ${ }^{[3,4, \text { for example] }}$. Clearly, the evaluation of temperature de-rating relies heavily on accurate real-time measurements and/or modelling of module operating temperature under varied environmental conditions.

Past research has examined both the efficacy of determining equivalent temperature coefficients that relate environmental conditions to PV module cell temperature ${ }^{[3]}$ and the effect of temperature sensor type on PV module thermal measurements ${ }^{[13-15]}$. In the latter work, temperature sensing devices ranging from semiconductor devices to standard thermocouples were used to provide PV backside temperature measurements in field-based studies. In that work, the thermocouple devices were found to provide the most accurate temperature readings of the tested device types. It is known, however, that thermocouple devices with long leads can exhibit temperature errors due to resistance in the lead wires. For this reason, these sensors may not be the most practical for use with large or remote fielded PV arrays.

The current research investigates two alternative temperature measuring devices for application with fielded systems. The first is a precision integrated-circuit (IC) temperature device with an output voltage that is linearly-proportional to the temperature, while the second is a resistance temperature device (RTD) based on a temperature-dependent resistance. An analysis of PV module temperature was performed in laboratory using both the IC and RTD devices. A T-type thermocouple (TC) was also subjected to the testing simultaneously as a control device for comparative analysis. An overall comparison of the devices was then made in order to establish which was more suitable for quantifying PV module operating temperature. In addition, temperature gradient trends in a field-test environment were evaluated using a grid of TC's in order to examine the relationship between ambient and module temperature across an array of identical PV strings.

Reliability of Photovoltaic Cells, Modules, Components, and Systems IX, edited by Neelkanth G. Dhere, John H. Wohlgemuth, Keiichiro Sakurai, Proc. of SPIE Vol. 9938, 99380Q · (c) 2016 SPIE

CCC code: $0277-786 \mathrm{X} / 16 / \$ 18 \cdot$ doi: $10.1117 / 12.2237934$ 


\section{EXPERIMENTAL METHODS}

\subsection{Temperature Sensors}

As stated above, the three temperature sensors evaluated were the IC (Texas Instruments LM35), the RTD (OMEGA SA1-RTD) and the TC (T-type). The IC device was responsive from approximately $-55^{\circ} \mathrm{C}$ to $150^{\circ} \mathrm{C}$ with an accuracy of $\pm 0.75^{\circ} \mathrm{C}$ across that range. The RTD was rated for use from $-73^{\circ} \mathrm{C}$ to $260^{\circ} \mathrm{C}$ and its accuracy was $\pm 0.06^{\circ} \mathrm{C}$ at $0^{\circ} \mathrm{C}$. The T-type TC's used are considered to provide the best accuracy of common thermocouple device types with a measurement range of $-200^{\circ} \mathrm{C}$ to $350^{\circ} \mathrm{C}$ and typical accuracies of approximately $\pm 1.0^{\circ} \mathrm{C}$ at $0^{\circ} \mathrm{C}$. Figure 1 shows images of the RTD and IC devices (not to scale).
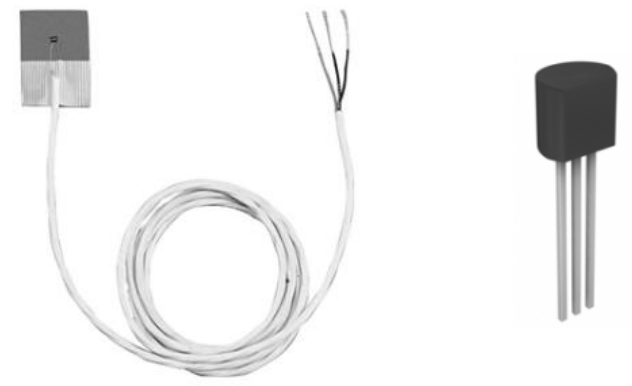

Figure 1: RTD (left) and IC device (right)

Electrical data were gathered using a Campbell Scientific CR800 datalogger. The CR800 is a smaller, research-grade datalogger designed for stand-alone operation in harsh, remote environments. Each CR800 reads input from sensors, then transmits the data via a communication peripheral. It is intended for smaller configurations in which fewer sensors will be measured. However, up to 32 additional channels were measured by utilizing an AM16/32B multiplexer. The AM16/32B multiplexer interfaces with the datalogger and adds terminals for wiring additional sensors of almost any type.

\subsection{Laboratory Testing}

The laboratory-based experiments described in this paper utilized both benchtop heaters and a large industrial-standard environmental chamber capable of enabling temperature control from $-30^{\circ} \mathrm{C}$ to $+100^{\circ} \mathrm{C} \pm 1.1^{\circ} \mathrm{C}$. A complete description of the chamber capabilities and configuration can be found in [4]. Testing included both an assessment of the ability of each of the devices to track rapid temperature fluctuations, and also an evaluation of net deviations in temperature readings between the IC, RTD and TC devices. In the first case, the test devices were exposed to rapid transient temperature profiles using a benchtop heater and the ability of each of the devices to track both rise and fall in temperature over the course of several minutes was examined. In the second test case, the devices were heated and cooled over the course of hours (quasi-steady-state) and comparisons in the devices ability to both track and maintain accurate temperature readings was assessed. These latter tests were performed in the environmental chamber and temperature profiles, at a maximum, mapped out a range from $0^{\circ} \mathrm{C}$ to $80^{\circ} \mathrm{C}$ for both devices and the TC standard. Throughout testing, instrumentation ports centered in the chamber side-walls allowed for the temperature sensors to be inserted into the chamber, while bundled together, with outputs analyzed in-situ and in real time. Data were collected, at a minimum, once per 10 seconds via the CR800. The success or failure of each device was determined by how well the data it produced matched that of the TC standard.

\subsection{Field Testing: TEP/AzRISE Test Yard}

Measurements on fielded PV modules to examine temperature trends across strings of modules and also across sections of a PV array, were performed at the TEP/AzRISE solar test yard. Located at $32^{\circ} \mathrm{N} 110^{\circ} \mathrm{W}$, the test yard houses more than 600 fixed (at $32^{\circ}$ facing south) photovoltaics modules from 20 different manufacturers, as well as a weather station 
that monitors ambient air temperature, relative humidity, wind speed, precipitation and irradiance. Dataloggers connected to the weather station and the module string outputs record the environmental profile once per 60 seconds.

Two strings, each consisting of 10 solar modules of the same technology, were selected to be instrumented with an array of thermocouples. Both strings were located in the same region of the test yard array however one was located in the front row of the array region while the other was located in the middle of the array region. The front string, therefore, faced its surrounding environment unimpeded by other strings, whereas the middle string was surrounded by the strings both in front and in back of it.

Twelve thermocouples were instrumented onto the back sides of the PV modules that comprised each string under test, as depicted in Figure 2. Temperature measurements were collected from each thermocouple, and from the test-yard weather station, once during every 60 seconds over the course of several weeks of testing. Tests to assure the accuracy of individual TC devices were also performed by swapping specific TC devices into different locations in the TC grid (see Fig. 2). This ensured that each of the devices was operating properly and that none were yielding systematic errors in their temperature readings, thus confirming that any acquired thermal data was location dependent rather than TC dependent. Examination of the data collected enabled an interpretation of the temperature variance across a single solar module, as well as across a string of solar modules, with respect to the string's location in the test yard.
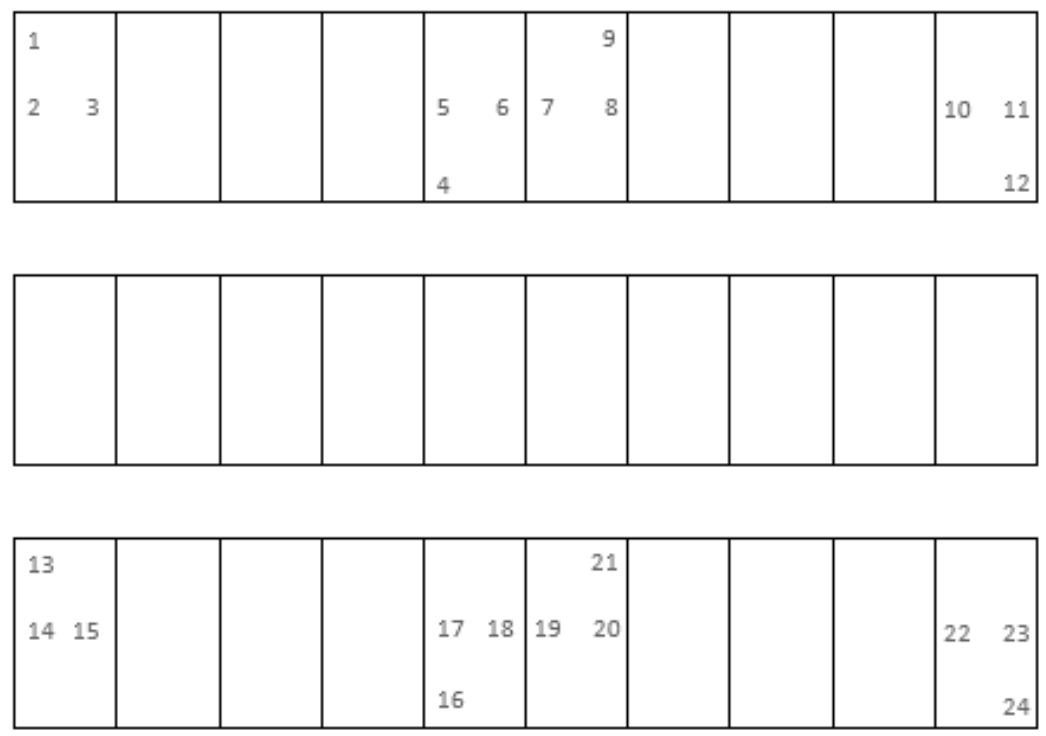

Figure 2: Test yard thermocouple configuration. Twelve TC devices were affixed to each of two strings of PV modules. The top row of modules (TC\#1-12) represents the front row of the array section under test while the bottom row (TC \#13-24) depicts a string in the middle of the array section under test.

\section{RESULTS AND DISCUSSION}

\subsection{Fast Transient Temperature Response}

The response of both the IC and RTD devices to temperature gradients provided by a benchtop heater was examined and representative data are shown in Figure 3 and Figure 4 respectively, below. In Figure 3 it is clearly seen that while the IC device closely tracked the TC temperature profile during the heating portion of the test, it failed to track the TC temperature for the rest of the profile. At the peak of the profile, the IC device reading was $3.5^{\circ} \mathrm{C}$ higher than the TC standard. An evaluation of all of the data taken on these devices indicated that the peak temperature error ranged from $3^{\circ} \mathrm{C}-10^{\circ} \mathrm{C}$ across all tested devices. In addition, Figure 3 shows that the IC device significantly overestimated the 
temperature during the cooling segment of the profile. Notably, the IC device reading was as much as $20^{\circ} \mathrm{C}$ higher than the TC standard during the first 30 seconds of cooling and only reached the TC temperature 2.5 minutes after the cooling cycle had begun.

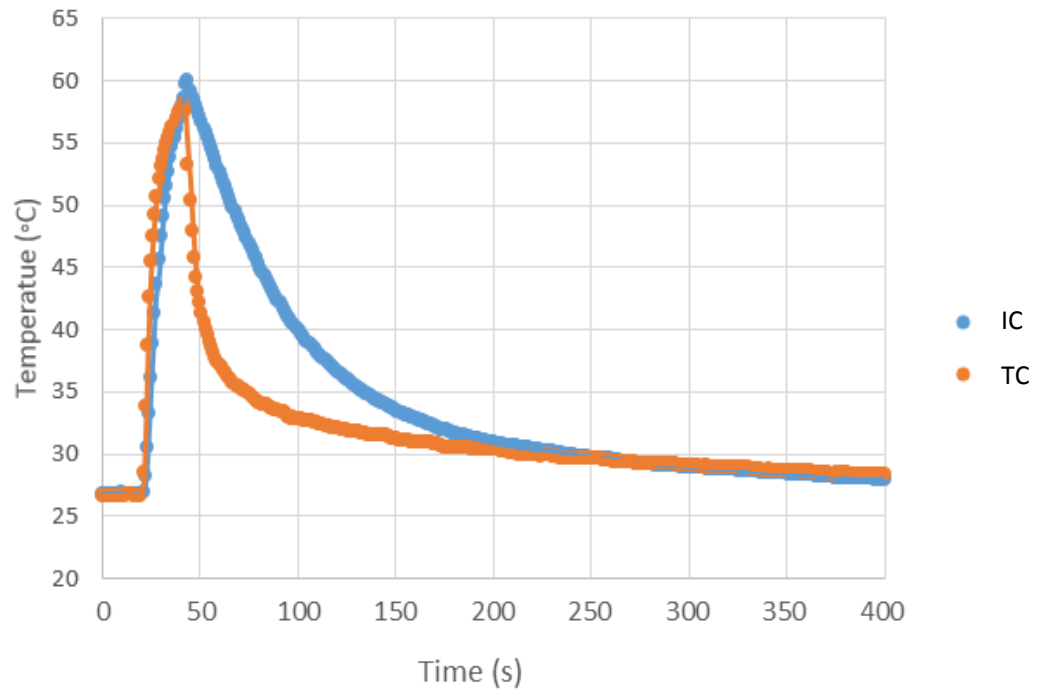

Figure 3: Transient temperature response of the IC sensor device as compared to the TC standard.

By contrast, Figure 4 compares the response of the RTD to the TC standard. Examination of the figure shows that the RTD device also overestimated the TC temperature reading during the heating portion of the profile, leading to an error of approximately $7^{\circ} \mathrm{C}$ at peak temperature in this data profile. An analysis the data acquired on these devices indicated errors in peak temperature ranging from $1{ }^{\circ} \mathrm{C}$ to $10^{\circ} \mathrm{C}$ across all data. During the cooling portion of the profile, however, the RTD exhibited high accuracy, closely matching the TC standard with the RTD device reading temperatures within $2^{\circ} \mathrm{C}$ of the TC at all times. Thus, while neither the IC nor the RTD precisely matched the TC-standard transient temperature profile, the performance of the RTD provided a closer equivalent to the TC.

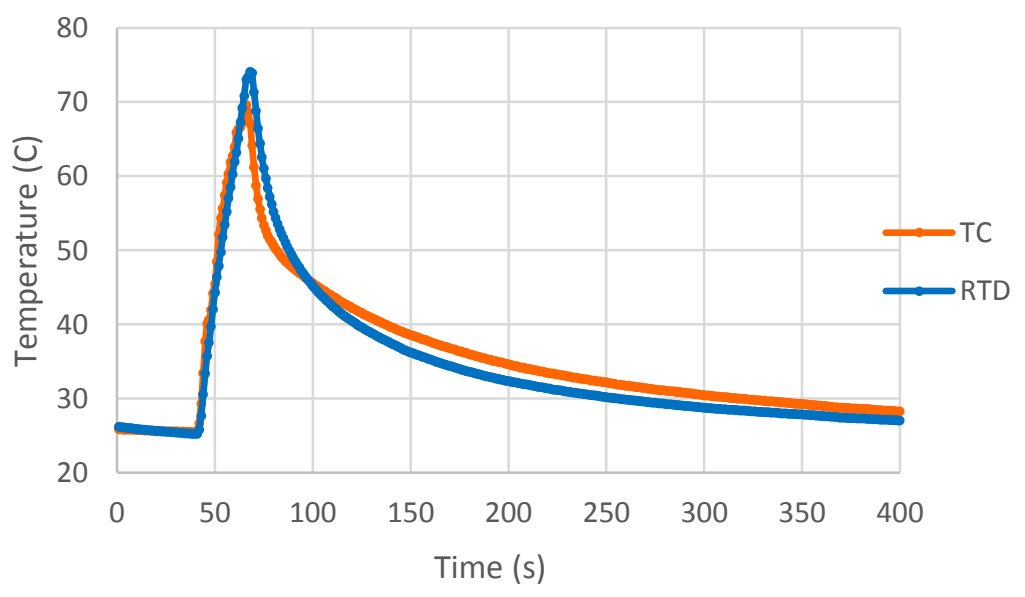

Figure 4: Transient temperature response of the RTD sensor device as compared to the TC standard. 


\subsection{Quasi-Steady-State Temperature Response}

As described in 2.2, above, both the IC and RTD devices, along with the TC standard, were evaluated over longer time scales in which the devices were subjected to more gradual temperature gradients over the course of testing. Figure 5 shows the results of this testing on all of the devices. As can be seen in the figure, both the TC and the RTD devices closely tracked the TC device over the range of temperatures tested and over the time scales represented. Close examination of the data indicated that all of the devices readings were within $\pm 2{ }^{\circ} \mathrm{C}$ of each other throughout the test cycle.

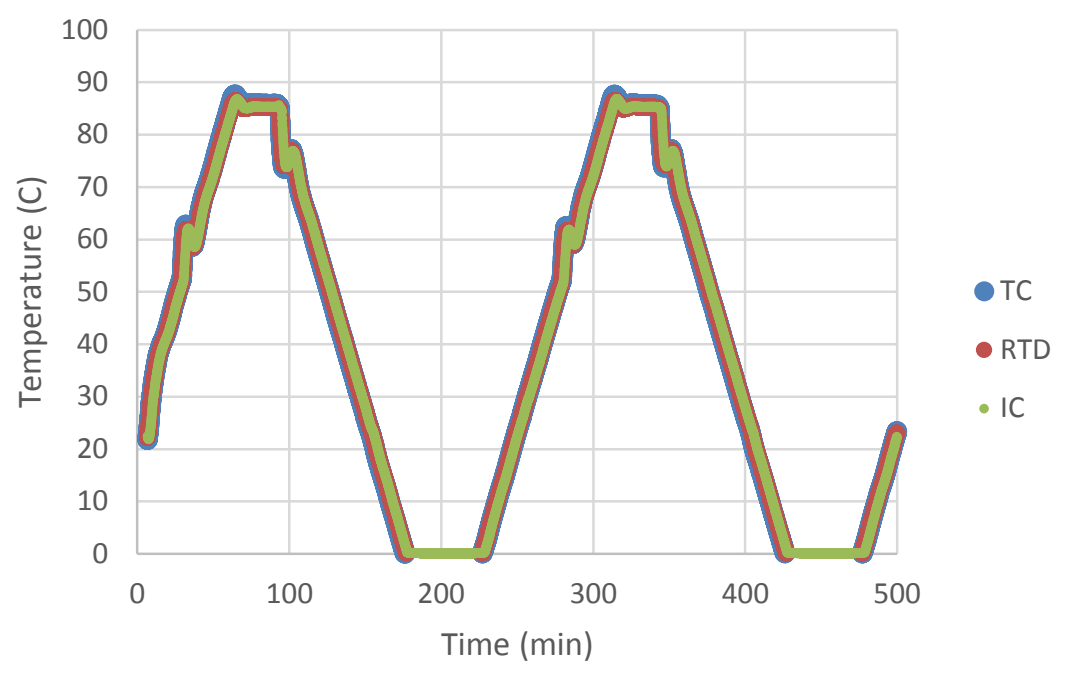

Figure 5: IC and RTD temperature devices compared with TC standard in thermal chamber testing.

Longer time-scale testing was also performed on the IC and TC devices using thermal conditions similar to those of a fielded PV system. In this case, a close examination of the temperature response of the IC device subject to a slow temperature ramp over the course of more than 6 hours was performed. Temperature ramp and set points were based on reasonable equivalent profiles for fielded PV system temperatures in Tucson, AZ during typical late-summer months.

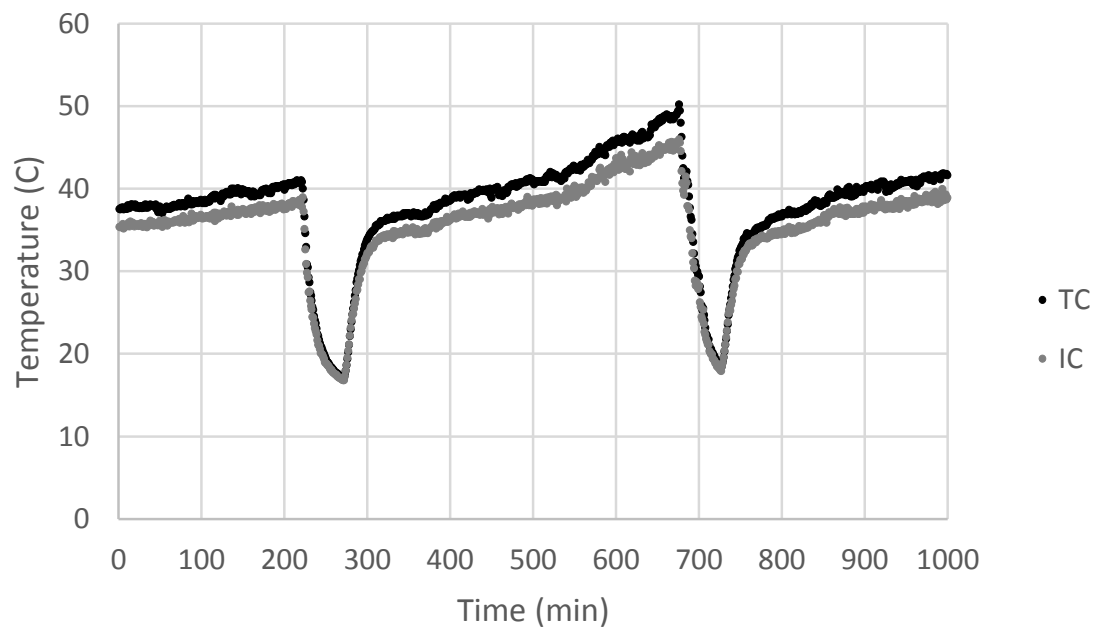

Figure 6: Comparison of IC and TC devices in thermal chamber with long time scale temperature ramp. 
The data are shown in Figure 6 and a small but persistent deviation between the IC device and the TC standard can be seen throughout the heating cycles of the testing. On average, although the IC device tracked the TC output throughout the test cycle, the IC device consistently under-predicted temperature by $2.5^{\circ} \mathrm{C}$. This trend was observed in all data taken under these test conditions. Given the large volume of the test chamber and the close proximity of the sensors, the deviation in device temperature readings between the IC and the TC can reliably be attributed to device performance and not to local variations in temperature within the chamber.

\subsection{Field-Test Studies}

As described in Section 2, two strings of PV modules located in an array at the Test Yard were instrumented with 24 TC sensors as in Figure 2. Data were collected on all of the TC devices and trends in temperature variation across modules and across strings were evaluated. While no trend in temperature gradient across an individual module was reliably noted, temperature variations between strings in the array were consistently observed. Figure 7 shows representative data taken from TC 12 (front module string) and TC 24 (middle module string) over the course of 2.5 days. Evident in the data is the day/night cycling that yields the overall variation from high to low temperatures across the test data. Variations in temperature on an hour-to-hour time scale can be correlated to local weather conditions (cloud cover, wind, etc.). More importantly, however, is the difference in TC temperature reading between the front and middle strings of the array. Notably, TC 24, located in the middle string of the array, consistently read a higher temperature than TC 12, located in the front string of the array, by as much as $6.5^{\circ} \mathrm{C}$ during daylight hours. This represents a significantly higher temperature deviation than the measured temperature accuracy of the TC devices. The trend was consistently observed across all of the data taken. For a typical polycrystalline PV module that exhibits an efficiency temperature de-rating decrease of $0.3 \%$ per ${ }^{\circ} \mathrm{C}$ to $0.5 \%$ per ${ }^{\circ} \mathrm{C}$, a location-dependent temperature change of over $6^{\circ} \mathrm{C}$ can lead to a significant decrease in $\mathrm{PV}$ efficiency and power output.

One possible interpretation for the position-dependent variation in PV string temperature may be that the unobstructed position of the font string in the array allowed it to be exposed to more favorable cooling from wind circulation than the mid-array string. This is significant, in that a correct evaluation of field-based degradation and temperature de-rating effects for PV modules mounted in array geometries will necessarily need to assess module temperatures not only at mid-string or mid-array locations but across front, middle and rear strings in the array.

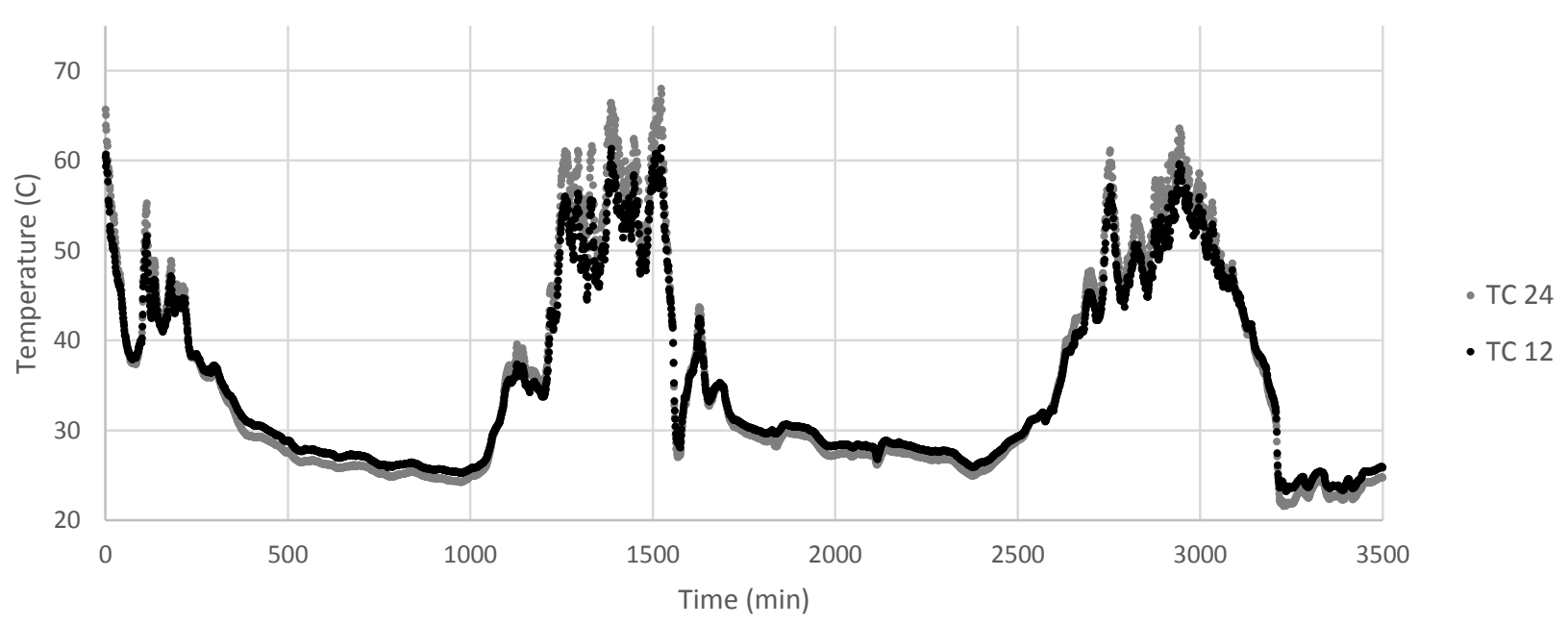

Figure 7: Front string thermocouple (TC 12) compared to middle string thermocouple (TC 24). Both thermocouples were in the same location on the strings (see Fig. 2). 


\section{CONCLUSIONS}

The purpose of this research was two-fold: first, to determine the functionality and accuracy of the IC and RTD devices as compared to a T-type thermocouple (TC) standard, and, second, to evaluate temperature gradient effects in arraybased field-test experiments. The two devices tested, an OMEGA SA1-RTD and a Texas Instruments LM35 IC, were thoroughly tested and analyzed. Test results illustrated that the IC device significantly deviated from the baseline TC standard when monitoring fast, transient, thermal profiles but reasonably reported temperature when slower temperature profiles were applied. By contrast, the RTD device closely matched the temperature profile of the TC standard in all test configurations.

An investigation of fielded PV array temperature-gradient effects using the TC standard was also performed. From these data it may be concluded that a significant increase in module backside temperature was observed for PV modules located mid-array as opposed to in the front row of an array. This finding has consequences when assessing overall asset degradation and return-on-investment for large PV array facilities. Ongoing research is underway to evaluate trends in temperature gradients across single strings and within larger PV array geometries for fielded systems. Additionally, other weather factors need to be closely studied prior to, and while, collecting PV temperature data in order to establish a mechanistic explanation of the observed filed-based trends.

\section{ACKNOWLEDGEMENTS}

This work was supported by the Arizona Research Institute for Solar Energy (AzRISE) and by Tucson Electric Power Corporation (TEP).

\section{REFERENCES}

[1] King, D. L., Kratochvil, J. A., and Boyson, W. E., "Temperature Coefficients for PV Modules and Arrays: Measurement Methods. Difficulties and Results," Proc. 26th IEEE Photovoltaics Specialists Conf. (PVSC), Anaheim, September 29-October 3, pp. 1183-1186 (1997).

[2] Skoplaki, E., and Palyvos, J. A., , "On the Temperature Dependence of Photovoltaic Module Electrical Performance: A Review of Efficiency/Power Correlations," Sol. Energy, vol. 83, pp. 614-624 (2009)

[3] Kurtz, S., Whitfield, K., TamizhMani, G., Koehl, M., Miller, D., Joyce. J., Wohlgemuth, J., Bosco, N., Kempe, M. and Zgonena, T., "Evaluation of high-temperature exposure of photovoltaic modules," Prog. Photovolt: Res. Appl., vol. 19, pp.954-965 (2011).

[4] Lai, T., Biggie, R., Brooks, A., Potter, Jr., B. G., and Simmons-Potter, K., "Environmental aging in polycrystallineSi photovoltaic modules: Comparison of chamber-based accelerated degradation studies with field-test data," Proc. of SPIE, vol. 9563 pp. 956309-1 - 956309-8, (2015).

[5] Laronde, R., Charki, A. and Bigaud, D., "Lifetime estimation of a photovoltaic module subjected to corrosion due to damp heat testing," Journal of Solar Energy Engineering, Trans. ASME, vol. 135(2), pp. 021010-1 - 021010-8 (2013).

[6] Charki, A., Laronde, R., and Bigaud, D., "The time-variant degradation of a photovoltaic system," Journal of Solar Energy Engineering, Trans. ASME, vol. 135(2), pp. 024503-1 - 024503-4 (2013).

[7] Jordan, D. C. and Kurtz, S. R,. "Photovoltaic degradation rates - An analytical review," NREL JA-5200-51664 (2012).

[8] Kurtz, S., Granata, J., and Quintana, M., "Photovoltaic-reliability R\&D toward a solar-powered world," Proc. SPIE, vol. 7412, $7412 \mathrm{OZ}$ (2009).

[9] McMahon, T. J., "Accelerated testing and failure of thin-film PV modules," Prog. Photovolt: Res. Appl., vol. 12, no. 2-3, pp. 235-248 (2004).

[10] Cuddihy, E. F., "The aging correlation $(\mathrm{RH}+\mathrm{t})$ : relative humidity $(\%)+$ temperature $(\mathrm{C})$, , Corrosion Science, vol. 1, no. 5, pp. 463-474 (1987).

[11] Sugimura, R. S., Wen, L. C., Mon G. R., and Ross, R. G. J., "Test techniques for voltage/humidity-induced degradation of thin-film photovoltaic modules," Solar Cells, vol. 28, pp. 103-114 (1990).

[12] Jeong, J.-S., Park N. and Han, C., "Field failure mechanism study of solder interconnection for crystalline silicon 
photovoltaic module," Microelectronics Reliability, vol. 52, pp. 2326-2330 (2012).

[13] Jankovec, M. and Topič, M., "Intercomparison of Temperature Sensors for Outdoor Monitoring of Photovoltaic Modules,” Journal of Solar Energy Engineering, vol. 135, pp. 031012-1 - 031012-7 (2013).

[14] Kurnik, J., Jankovec, M., Brecl, K. and Topic", M., "Outdoor Testing of PV Module Temperature and Performance Under Different Mounting and Operational Conditions," Sol. Energy Mater. Sol. Cells, vol. 95(1), pp. 373-376 (2011).

[15] Krauter, S. and Preiss, A., "Comparison of Module Temperature Measurement Methods," Proc. of 34th Photovoltaic Specialists Conf.(PVSC), Philadelphia, PA, June 7-12, pp. 333-338 (2009). 